\title{
Comparative analysis of soybean genotype resistance to Heterodera glycines and Meloidogyne species via resistance gene analogs
}

\author{
P.M.H. Vieira ${ }^{1}$, F.A.S. Arêdes ${ }^{2}$, A. Ferreira ${ }^{3}$ and M.F.S. Ferreira ${ }^{1}$ \\ ${ }^{1}$ Laboratório de Melhoramento Genético Vegetal, Departamento de Biologia, \\ Centro de Ciências Agrárias, Universidade Federal do Espírito Santo, Alegre, \\ ES, Brasil \\ ${ }^{2}$ Universidade Estadual Norte Fluminense, Campos dos Goytacazes, RJ, Brasil \\ ${ }^{3}$ Laboratório de Melhoramento Genético Vegetal, \\ Departamento de Produção Vegetal, Centro de Ciências Agrárias, \\ Universidade Federal do Espírito Santo, Alegre, ES, Brasil \\ Corresponding author: M.F.S. Ferreira \\ E-mail: marcia.ferreira@ufes.br
}

Genet. Mol. Res. 15 (3): gmr.15038562

Received February 17, 2016

Accepted March 28, 2016

Published September 2, 2016

DOI http://dx.doi.org/10.4238/gmr.15038562

Copyright (C) 2016 The Authors. This is an open-access article distributed under the terms of the Creative Commons Attribution ShareAlike (CC BY-SA) 4.0 License.

ABSTRACT. Nematodes are important pests of soybean throughout
the world and cause high yield losses. As a control strategy, the
identification of resistance genes is an important aim of breeding studies.
Plants possess resistance genes (R), which are responsible for the
recognition of pathogens and activation of the defense system. R genes
and resistance gene analogs (RGAs) possess conserved domains, from
which nucleotide-binding site is the most common. Using degenerate
primers originating from these domains, it is possible to identify and
isolate sequences of R and RGA genes. In this study, soybean genotypes
resistant to the nematodes Heterodera glycines, Meloidogyne incognita,

Genetics and Molecular Research 15 (3): gmr.15038562 
M. javanica, and M. enterolobii were compared by the use of RGAs and simple sequence repeat (SSR) markers. Forty-six soybean genotypes were studied, including plant introductions (PIs), commercial crops, and source of resistance genotypes. Thirteen combinations of RGA primers and different SSRs linked to QTLs were used to confirm resistance to soybean cyst nematodes ( $\mathrm{SCN})$. Fragments associated with resistance to the studied nematodes were amplified in the source of resistance and PI genotypes. RGA markers were efficient at distinguishing groups of genotypes that were resistant and susceptible to Meloidogyne spp and SCN. Combinations of specific primers were identified through their ability to amplify nucleotide sequences from possible resistance candidate genes. SSR markers contributed to the analysis of SCN race specificity, showing that the QTLs identified by these markers are distinct from those identified by RGA markers.

Key words: Soybean resistance; Nematode; Resistance gene analogs; Conserved domains; Molecular markers

\section{INTRODUCTION}

Soybean nematodes such as Heterodera glycines, Ichinohe, and Meloidogyne species are serious global soybean pests. Other than rotation with non-host crops, breeding cultivars with resistance to multiple nematode species is the most effective and environmentally friendly method to control these pests. Molecular strategies have been used to breed for nematode resistance for many years (Concibido et al., 2004; Jiao et al., 2015). The identification of molecular markers associated with resistance is helpful for developing resistant cultivars because phenotyping soybean for nematode resistance is time-consuming and costly (Kadam et al., 2016). Transgenic approaches have not been reported for soybean resistance to nematodes; however, marker assisted selection has been broadly studied and reported in soybean against other pests (Concibido et al., 2004; Xiao et al., 2014). In this context, strategies used to identify molecular markers for nematode resistance using those based on plant resistance genes (R genes) and the so-called resistance gene analogs (RGA) constitute one alternative that has not yet been employed in soybean.

$\mathrm{R}$ genes mediate a mechanism of resistance that is specific against pathogens, and which developed during the coevolution of plant-pathogen interactions (Kang et al., 2012; Sekhwal et al., 2015). Through this mechanism, products of the $\mathrm{R}$ genes recognize elicitors originating from pathogens and subsequently initiate the resistance response (Flor, 1971; Thakur and Sohal, 2013).

The proteins that recognize elicitor molecules share conserved domains that fulfill specific functions, such as recognition, protein-protein interaction, signaling, and activities that initiate the resistance response (Lei et al., 2014). Domains found in the majority of sequenced $\mathrm{R}$ genes include leucine-rich repetitions (LRR), nucleotide-binding sites (NBS), leucine zipper domains, coiled-coil (CC) domains, protein-protein interaction domains homologous to the interleukin-1 receptor (Toll/interleukin-1 receptor), and transmembrane (TM) domains, as well as other domains such as nuclear localization signal (NILS), tryptophan-arginine-lysinetyrosine (WRKY), domain, and kinase domains (Collins et al., 1998; Gururani et al., 2012). In addition to $\mathrm{R}$ genes, a class of potential resistance genes, the RGAs, is characterized by the presence of conserved domains. RGAs are important in the study of resistance and in

Genetics and Molecular Research 15 (3): gmr.15038562 
the research and understanding of $\mathrm{R}$ gene evolution, and are found widely in the genomes of various species (Sekhwal et al., 2015).

Conserved domains are clustered in different arrangements, resulting in eight classes (Williamson and Kumar, 2006), which are all represented by products of the R genes and have been recognized and validated in monocot and dicot species (Gururani et al., 2012; Sanseverino and Ercolano, 2012). NBS-LRR represents the best known family of RGAs. The NBS domain can be identified in the genome by its motifs, namely P-loop, kinase 2, kinase 3, and GLPL, which enable the isolation and cloning of R genes and RGAs (Yu et al., 1996; Shen et al., 1998; Lei et al., 2014).

It is important to identify the genes in the soybean crop, Glycine max (L.) Merril, that are related to defense against potential pathogenic agents, including Heterodera glycines, the soybean cyst nematode (SCN) (Vuong et al., 2015), and nematodes of the genus Meloidogyne, both of which cause substantial yield losses. The first cloned $\mathrm{R}$ gene conferring resistance to a nematode was $H s 1^{\text {pro-l }}$ in sweet potato, for resistance to Heterodera schachtii (Cai et al., 1997). The conserved domains of this gene are of the LLR-TM type. The genes rhg1 and Rhg4 (Vuong et al., 2015), which contain LLR-TM-Kinase domains, are reported to confer resistance to H. glycines in soybean. The genes $\mathrm{Cre}-\mathrm{I}$ and $\mathrm{Cre}-2$, with NBS-LRR domains, confer resistance to the nematode Heterodera avenae. As for Meloidogyne, the genes Mi-1 and Mi-9 are reported to be responsible for resistance, and possess domains CC-NBS-LRR and $\mathrm{Me}-3$ in pepper (Gururani et al., 2012).

In addition to RGAs, resistance loci can be identified by microsatellite markers (Sekhwal et al., 2015), which are widely distributed in the genomes of eukaryotes and are frequently used to map resistance genes. Given the complexity of SCN resistance, which is controlled by quantitative trait loci (QTLs) (Concibido et al., 2004; Kim et al., 2010), simple sequence repeat (SSR) markers have often been used to identify QTLs associated with resistance (Vuong et al., 2015).

Molecular markers are useful for the identification of $\mathrm{R}$ genes in commercial cultivars and to identify possible sources of resistance. The use of resistant cultivars is one of the most efficient methods in the control of $H$. glycines and Meloidogyne spp; however, this strategy is limited, as those genotypes are generally derived from a common parent, such as PI 88788 or Peking. Therefore, it is important to identify new sources of resistance to these nematodes.

The molecular comparison of groups of genotypes that are resistant and susceptible to nematodes may contribute to the research of $\mathrm{R}$ genes and to the identification of genomic regions that are present in resistant genotypes. In the present study, polymorphisms were identified by RGA markers originating from the NBS domain, which is the most common domain found in resistance genes. In addition, the results were compared using microsatellite markers linked to QTLs, either for resistance, in the case of SCN, or in genotypes resistant and susceptible to nematodes in soybean. Hence, this study aimed to identify differential regions of the soybean genome that are related to resistance against nematodes of the genus Meloidogyne spp and the species $H$. glycines in soybean genotypes by means of RGA and SSR markers.

\section{MATERIAL AND METHODS}

\section{Plant material}

The 46 soybean genotypes used in this study were provided by Empresa Brasileira de Pesquisa Agropecuária (Embrapa) and the Institute of Biotechnology Applied to Agriculture (Bioagro). The genotypes used were selected based on the literature, with the aim of obtaining groups of genotypes that are resistant and susceptible to nematodes of the genus Meloidogyne

Genetics and Molecular Research 15 (3): gmr.15038562 
(M. javanica, M. incognita, and M. enterolobii) and to different races of $H$. glycines, and SCN (Table 1). Among the genotypes used, 32 were cultivars obtained by four different breeding programs in Brazil (Embrapa, Coodetec, Fundação Mato Grosso, and UFV).

Table 1. Nematode resistance of the soybean genotypes used in this study.

\begin{tabular}{|c|c|c|c|c|c|}
\hline Genotype / BP - O & Resistance to SCN & $M i$ & $M j$ & $M e$ & Parents \\
\hline CD201 / CD & $\mathrm{S}$ & $\mathrm{R}$ & $\mathrm{R}$ & $\mathrm{S}$ & - \\
\hline CD217 / CD & R 3 & $\mathrm{R}$ & $\mathrm{S}$ & $\mathrm{S}$ & - \\
\hline Conquista / E & $\mathrm{S}$ & $\mathrm{R}$ & $\mathrm{R}$ & $\mathrm{S}$ & - \\
\hline BRS $211 / \mathrm{E}$ & - & $\mathrm{R}$ & $\mathrm{R}$ & $\mathrm{T}$ & - \\
\hline BRS Valiosa / E & $\mathrm{S}$ & MR & $\mathrm{R}$ & $\mathrm{T}$ & - \\
\hline BRS 256RR / E & $\mathrm{S}$ & $\mathrm{R}$ & $\mathrm{R}$ & $\mathrm{T}$ & - \\
\hline BRS Raimunda / E & $\mathrm{S}$ & $\mathrm{R}$ & $\mathrm{R}$ & $\mathrm{T}$ & - \\
\hline BRSG Paraíso / E & - & $\mathrm{R}$ & $\mathrm{R}$ & $\mathrm{T}$ & - \\
\hline Luziânia / E & $\mathrm{S}$ & MR & $\mathrm{R}$ & $\mathrm{S}$ & - \\
\hline BRS Favorita / E & $\mathrm{S}$ & MR & $\mathrm{R}$ & $\mathrm{T}$ & - \\
\hline BRSGO Iara / E & $\mathrm{R} 1,3$ & $\mathrm{~S}$ & $\mathrm{~S}$ & - & Peking (S) \\
\hline BRS262 / E & $\mathrm{R} 1,3$ & $\mathrm{~S}$ & $\mathrm{~S}$ & - & Peking (S); PI $437654(\mathrm{H})$ \\
\hline BRSGO Raissa / E & $\mathrm{R} 1,3$ & $\mathrm{~S}$ & $\mathrm{~S}$ & - & Peking (S) \\
\hline BRS Invernada / E & $\mathrm{R} 1,3$ & $\mathrm{~S}$ & $\mathrm{~S}$ & - & Peking(S); PI 88788; PI 209332 \\
\hline BRSGO Chapadões / E & $\mathrm{R} 1,2,3,4,5,14$ & MR & $\mathrm{S}$ & - & PI $437654(\mathrm{H})$ \\
\hline BR Jiripoca / E & $\mathrm{R} 1,3,14$ MR 5, 6, 9, 1 & $\mathrm{~S}$ & $\mathrm{~S}$ & - & Peking (S); PI $437654(\mathrm{H})$ \\
\hline BRS263 D / E & R 1, 3 MR 14 & $\mathrm{~S}$ & $\mathrm{~S}$ & - & Peking (S; F; L); PI 437654 (H) \\
\hline TMG115 / FMT & R 1, 3 MR 14 & $\mathrm{~S}$ & $\mathrm{~S}$ & - & Peking; PI 437654 \\
\hline TMG121RR / FMT & $\mathrm{R} 1,3 \mathrm{MR} 14$ & $\mathrm{~S}$ & $\mathrm{~S}$ & - & Peking; PI 437654 \\
\hline Tucunaré / FMT & R 1, 3 MR 14 & $\mathrm{~S}$ & $\mathrm{~S}$ & - & Peking (S); PI 437654(H) \\
\hline Tabarana / FMT & $\mathrm{R} 1,3$ & $\mathrm{~S}$ & $\mathrm{~S}$ & - & Peking (Centennial) \\
\hline TMG117 / FMT & R 3 & $\mathrm{~S}$ & $\mathrm{~S}$ & - & - \\
\hline Doko / FMT & $\mathrm{S}$ & $\mathrm{S}$ & $\mathrm{S}$ & $\mathrm{S}$ & - \\
\hline M-Soy $8400 / \mathrm{MO}$ & R 3 & - & - & - & Peking (Coker) \\
\hline M-Soy $8001 /$ MO & $\mathrm{R} 1,3$ & $\mathrm{~S}$ & $\mathrm{~S}$ & $\mathrm{~S}$ & Peking (Coker 6738) \\
\hline M-Soy $6106 / \mathrm{MO}$ & $\mathrm{S}$ & - & - & - & - \\
\hline M-Soy 8914 / MO & $\mathrm{S}$ & - & - & - & - \\
\hline Y23 / UFV & $\mathrm{S}$ & - & - & - & - \\
\hline UFVS2001 / UFV & $\mathrm{S}$ & - & - & - & - \\
\hline UFV16 / UFV & S & - & - & - & - \\
\hline UFVTN104 / UFV & $\mathrm{S}$ & - & - & - & - \\
\hline UFV18 / UFV & $\mathrm{S}$ & - & - & - & - \\
\hline A7002 & $\mathrm{S}$ & - & - & - & - \\
\hline Bedford** & $\mathrm{R}$ & - & - & $\mathrm{S}$ & PI 88788 \\
\hline PI 595099 & $\mathrm{R}$ & $\mathrm{R}$ & $\mathrm{R}$ & $\mathrm{R}$ & - \\
\hline PI 594427 & $\mathrm{R}$ & $\mathrm{R}$ & $\mathrm{R}$ & $\mathrm{R}$ & - \\
\hline PI 209332 / Japan & $\mathrm{R} 3,5,14$ & - & - & - & - \\
\hline PI 548316 / China & R 3 MR 14 & - & - & - & - \\
\hline PI 88788 / China & R 3, 14 & - & - & - & - \\
\hline PI 90763 / China & $\mathrm{R} 1,2,3,5$ & - & - & - & - \\
\hline PI 437654 / Russia & $\mathrm{R}^{*}$ & - & - & - & - \\
\hline PI 89772 / China & $\mathrm{R} 1,2,3,5 \mathrm{MR} 14$ & - & - & - & - \\
\hline Hartwig / USA & $\mathrm{R} * \mathrm{E} 4^{+}, 14^{+}$ & - & - & - & PI 437654 \\
\hline Pickett / USA & $\mathrm{R} 1,3$ & - & - & - & - \\
\hline Peking / USA & $\mathrm{R} 1,3,5$ & - & - & - & - \\
\hline Lee & $\mathrm{S}$ & - & - & - & - \\
\hline
\end{tabular}

BP: breeding program; E: EMBRAPA; CD: COODETEC; FMT: Fundação Mato Grosso; O: origin; SCN: soybean cyst nematode; Mi: Meloidogyne incognita; Mj: Meloidogyne javanica; Me: Meloidogyne enterolobii. R: resistant; *R resistant to all races of SCN; MR: moderately resistant; T: tolerant; S: susceptible; resistance from Peking, S (Sharkey); F (Forrest); Centennial; Coker; L (Lancer, Lancer x BR80-6989). Resistance from PI437654, H (Hartwig). ${ }^{* *}$ Resistance from PI88788. Source: EMBRAPA (2011).

Genetics and Molecular Research 15 (3): gmr.15038562 


\section{Molecular analyses}

Genomic DNA was extracted from seeds using an adaptation of the method described by McDonald et al. (1994). The quality and concentration of the DNA were verified using a spectrophotometer Nanodrop ${ }^{\mathrm{TM}} 2000$ (Thermo Scientific) and integrity was confirmed by $0.8 \%$ agarose gel electrophoresis. For the polymerase chain reaction (PCR), 13 combinations of degenerate primers were used, originating from the NBS domain of the RPS2 gene of Arabidopsis thaliana, which confers resistance to Pseudomonas syringae; from the $N$ gene of tobacco, which confers resistance to the tobacco mosaic virus (Leister et al., 1996; Shen et al., 1998), and from the $L 6$ gene of linen, which confers resistance to Melampsora lini (Table 2). Combinations of these RGA primers were amplified in a final volume of $20 \mu \mathrm{L}$ containing 1X Master Mix (Fermentas), $30 \mathrm{ng}$ DNA, $0.4 \mu \mathrm{M}$ each primer, and $1 \mathrm{U}$ Taq DNA polymerase. The reactions were subjected to initial denaturation for $5 \mathrm{~min}$ at $94^{\circ} \mathrm{C}$, followed by 35 cycles of $1 \mathrm{~min}$ at $94^{\circ} \mathrm{C}, 1 \mathrm{~min}$ at $40^{\circ} \mathrm{C}$, and $2 \mathrm{~min}$ at $72^{\circ} \mathrm{C}$, with a final extension of $10 \mathrm{~min}$ at $72^{\circ} \mathrm{C}$. The PCR products were separated by gel electrophoresis on $1.4 \%$ agarose, stained with ethidium bromide, and visualized under ultraviolet light. Twenty-eight combinations of the RGA primers S2, As1, As2, As3, LM637, F1, and R1 were evaluated. To confirm the results, the reactions were repeated up to three times.

Table 2. Resistance gene analogue primers used in the present study that were obtained from the nucleotidebinding site (NBS) domain.

\begin{tabular}{l|l|l|l|l}
\hline Primer & Motif & Gene $(\mathrm{s})$ & Sequence 5'-3' & Reference \\
\hline s1 & P-loop & $N, L 6, R P S 2$ & GGTGGGGTTGGGAAGACAACG & 1 \\
\hline s2 & P-loop & $N, L 6, R P S 2$ & GGIGGIGTIGGIAAIACIAC & 1 \\
\hline As1 & GLPL & $N, L 6, R P S 2$ & CAACGCTAGTGGCAATCC & 1 \\
\hline As2 & GLPL & $N, L 6, R P S 2$ & IAAIGCIAGIGGIAAICC & 1 \\
\hline As3 & GLPL & $N, L 6, R P S 2$ & IAGIGCIAGIGGIAGICC & 1 \\
\hline Ploop1 & P-loop & $N, L 6, R P S 2$ & AAGAATTCGGNGTNGGNAAAACAAC & 2 \\
\hline Ploop2 & P-loop & $N, L 6, R P S 2$ & AAGAATTCGGNGTNGGNAAAACTAC & 2 \\
\hline Ploop6 & P-loop & $N, L 6, R P S 2$ & AAGAATTCGGNGTNGGNAAGACAAC & 2 \\
\hline GLPL1 & P-loop & $N, L 6, R P S 2$ & AAGAATTCGGNGTNGGNAAGACTAC & 2 \\
\hline GLPL3 & GLPL & $N, L 6, R P S 2$ & AACTCGAGAGNGCNAGNGGNAGGCC & 2 \\
\hline F1 & GLPL & $N, L 6, R P S 2$ & AACTCGAGAGNGCNAGNGGNAGTCC & 2 \\
\hline LM637 & P-loop & $N, L 6, R P S 2$ & AACTCGAGAGNGCNAGNGGNAGCCC & 2 \\
\hline
\end{tabular}

Genes N, L6, and RPS2 are from Nicotiana tabacum, Linum usitatissimum, and Arabidopsis thaliana, respectively. Primers obtained from P-loop (or kinase 1a) domains = GGV/IGKTT; GLPL: GLPLAL. I = Inosina; R = G or A; Y $=\mathrm{T}$ or C; D =A, G, or T. 1: Leister et al. (1996); 2: Shen et al. (1998); 3: Pan et al. (2000); 4: Kanazin et al. (1996).

Amplifications were carried out in a total volume of $20 \mu \mathrm{L}$, containing $45 \mathrm{ng}$ genomic DNA, $0.4 \mu$ M each primer, $1 X$ Master Mix (Thermo Scientific), and 1.0 U Taq DNA polymerase (Fermentas). The reactions were carried out in a Veriti ${ }^{\circledR}$ 96-Well Thermal Cycler (Applied Biosystems) in accordance with the methods described by Leister et al. (1996) or Shen et al. (1998), depending on the combination of primers. The amplified products were separated by $1.5 \%$ agarose gel electrophoresis in $1 \mathrm{X}$ TBE buffer, stained with ethidium bromide, and visualized under UV light. To estimate the sizes of the amplified fragments, molecular weight markers of 100 bp were applied.

For comparative purposes, 25 genotypes with resistance to SCN were analyzed via RGA and SSR data. SSR data were obtained by Santana (2008) using SSRs linked to QTLs associated 
with SCN resistance. The genotypes compared were as follows: BRS 262, BRS 263 Diferente, BRS Invernada, BRS Jiripoca, BRSGO Chapadões, BRSGO Iara, BRSGO Raíssa, CD 217, MSoy-8001, MSoy-8400, TMG 115, TMG 117, TMG 121RR, FMT Tabarana, FMT Tucunaré, PI 209332, PI 437654, PI 548316, PI 89772, PI 88788, PI 90763, Pickett, Peking, Hartwig, and Lee.

\section{Data analyses}

The polymorphisms generated by RGAs were converted into a matrix of binary data. The matrix was used to determine dissimilarity between genotypes by the method of simple coincidence, with later performance of grouping by the hierarchical method of mean linkage between groups (UPGMA). Based on the SSR data, the dissimilarity matrix was obtained by pondered index, and was later used for grouping with the UPGMA method.

The obtained data were presented as a heat map, which is a multidimensional way of representing groupings and amplifications by genotype. Thereby, amplification was represented by a light color, and the absence of amplification by the red color. All analyses were performed using the $\mathrm{R}$ version 3.2.1 software. Inferences about differences between genotype groups were made using the Bayesian method with the Structure 2.3.4 software. The data were generated by the method of simple coincidence.

\section{RESULTS}

\section{RGA analysis}

RGA markers based on conserved motifs of the NBS domain amplified 80 amplicons, most of which were polymorphic (88.75\%), with a mean number of 7.72 amplicons per primer pair. Genotype diversity was estimated by the distance between individuals, which varied from 0.0 (CD201 and Doko) to 0.655 (TMG 115 and Peking). Clustering by the UPGMA method resulted in the formation of three groups (Figure 1, vertical clustering).

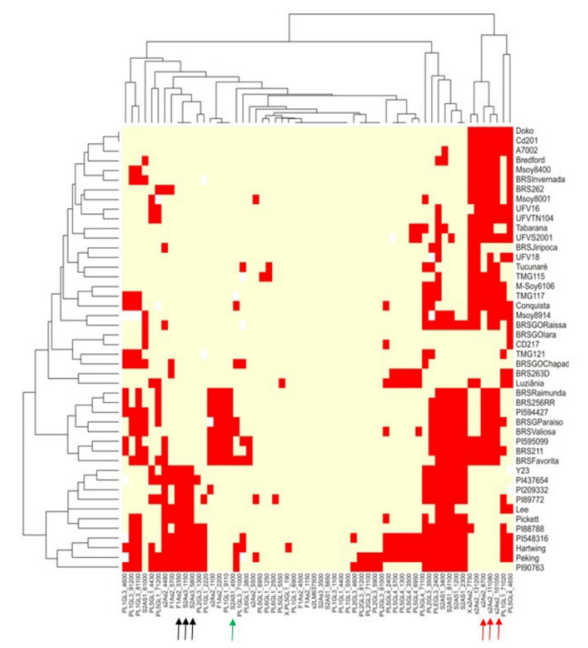

Figura 1. Amplification profile of RGA markers of 46 genotypes resistant and/or susceptible to Heterodera glycines or Meloidogyne nematode species. Grouping of genotypes (vertical); grouping of RGA amplicons (horizontal). 
Light yellow bands indicate amplification and red bands represent ausence of amplification. Black arrows: combinations of primers that amplify in resistant genotypes to Meloidogyne species; green arrow: combination of genotypes resistant to primer that amplifies the SCN and commercial genotypes resistant to at least one race of this nematode; red arrows: primer combinations that amplified prominently in the SCN resistance sources.

One of the groups, composed of $11 \mathrm{SCN}$-differentiator genotypes, contained sources of resistance that are used widely in Brazil and in the United States against SCN, including PI 437654 and Peking. For these genotypes, there are no reports of resistance to nematodes of the genus Meloidogyne spp. Differentiator genotypes susceptible to SCN (Lee and Y23) were also placed in this group.

A second group was constituted by soybean genotypes resistant and tolerant to the three Meloidogyne species, including the genotypes Raimunda, Paraíso, Valiosa, BRS 211, and BRS 256RR with tolerance to M. enterolobii (originated from Embrapa), in addition to the genotypes PI 595099 and PI 594427, which are resistant to all gall nematodes and to SCN. The greatest genetic proximity found within this group was between BRS 256 and BRS Valiosa (dissimilarity of 0.016).

The third group was composed of 27 commercial cultivars, of which 11 were susceptible to SCN (Conquista, CD 201, Luziânia, M-Soy6101, M-Soy8914, UFVS2001, UFV16, UFVTN104, UFV18, A7002, and Doko), three were resistant to race 3 (CD217, TMG117, M-Soy8400), six were resistant to races 1 and 3 (BRSGO Iara, BRS262, BRSGO Raissa, BRS Invernada, Tabarana, M-Soy 8001), four were resistant to races 1 and 3 and moderately resistant to race 14 (BRS263 Diferente, TMG115, TMG121RR, and Tucunaré), and two were resistant to more than three races (BRSGO Chapadões and BRS Jiripoca). The cultivars Conquista and CD201 are resistant to $M$. javanica and $M$. incognita. Six cultivars with known susceptibility to $M$. enterolobii were allocated to this group, which is composed of genotypes from the different breeding programs in Brazil (Embrapa, Fundação MT, COODETEC, and Monsanto).

In the structure analyses, the population was attributed a value of $\mathrm{K}=3$. The results corroborate the grouping of genotypes obtained by the UPGMA method (Figure 2). The largest group was composed of cultivars originating from different breeding programs, and contained individuals that were resistant and susceptible to SCN and Meloidogyne spp. The second group was formed by differentiator genotypes and sources of resistance to SCN. The last group was allocated genotypes that were mostly resistant to $M$. incognita and $M$. javanica, besides PI 595099 and PI 594427.

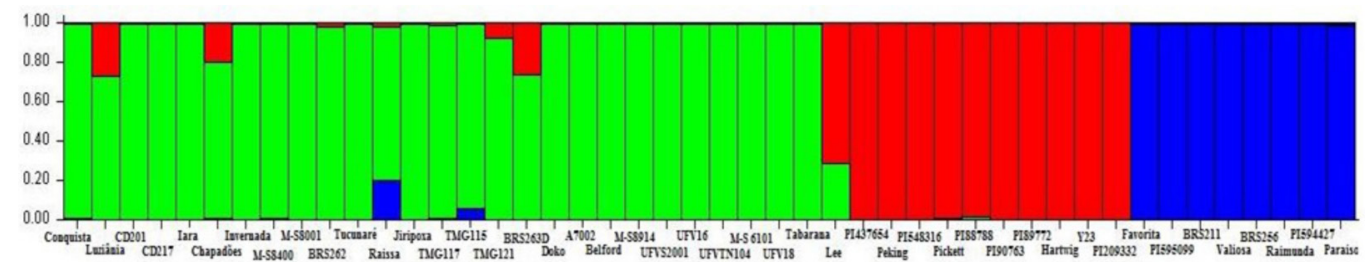

Figure 2. Structure analysis of 46 soybean genotypes by all RGA markers. Clusters were inferred based on Bayesian analyses considering the most probable number of groups $(K=3)$ estimated.

The primer combinations used to amplify motifs of the NBS domain, which were obtained from resistance genes of A. thaliana and $N$. tabacum, were analyzed independently in order to characterize the influence of the primers on the grouping of genotypes (Figure 3A and B).

Genetics and Molecular Research 15 (3): gmr.15038562 

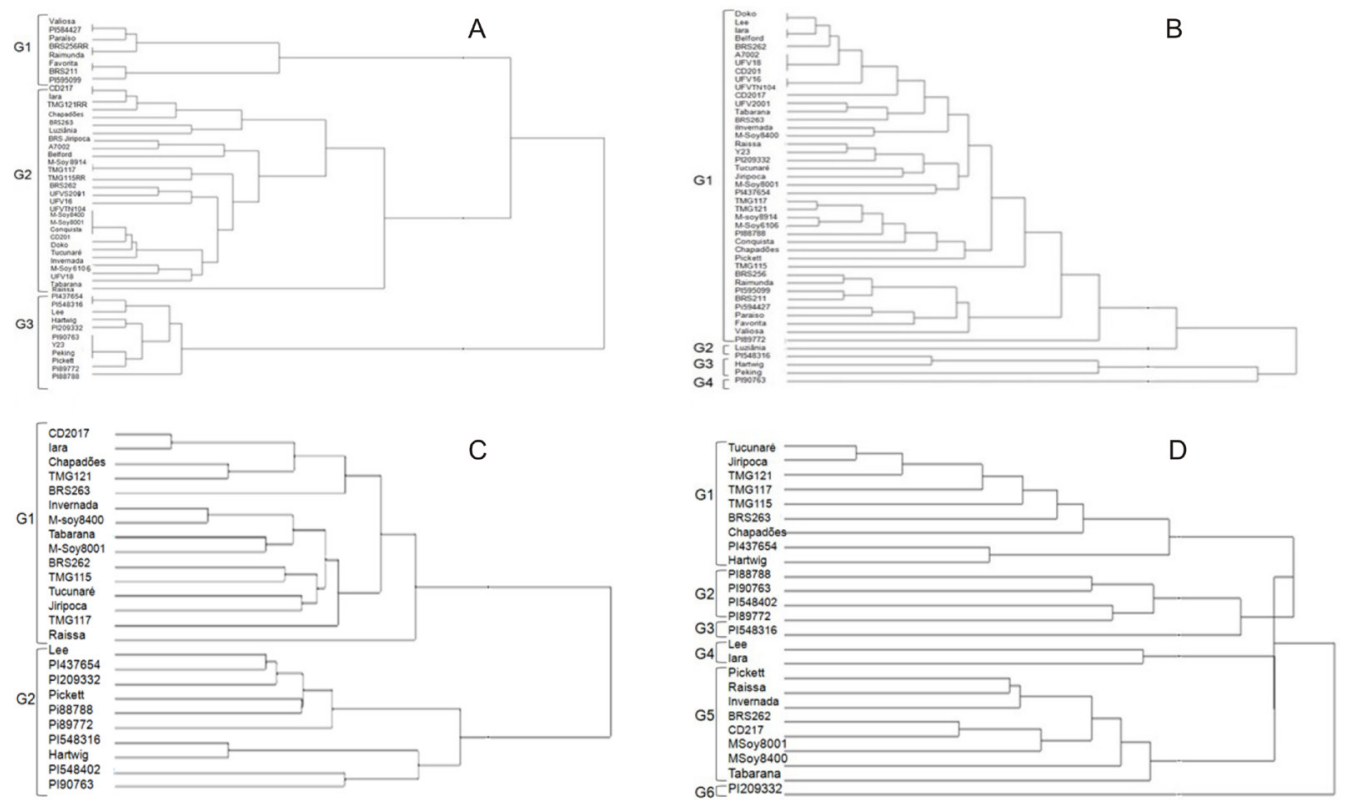

Figura 3. Clustering of 46 soybean genotypes resitant to nematodes via RGA markers obtained by Leister et al. (1996) (A) or Shen et al. (1998) (B). Clustering of 25 soybean genotypes resitant to SCN by RGAs markers (C) and SSR markers linked to QTL for resistance to SCN (D).

The initial grouping (Figure 1) was maintained with the primers s1, s2, As1, As2, and As3 (Figure 3A). Polymorphisms generated by combinations of the P-loop (P- loop 1, P-loop 2, P-loop 3, P-loop 4, P-loop 5, and P-loop 6) and GLPL (LM637, GLPL1, GLPL3, and GLPL4) primers did not maintain the subgroups observed in the clustering using all primers (Figure 3B). However, the group of genotypes with resistance to the genus Meloidogyne spp remained the same in all analyses, showing that the two primer sets assessed similar regions in the genome of these genotypes.

In addition to the grouping of genotypes, fragments amplified by RGA were also clustered in order to facilitate the identification of contrasting genomic regions between the groups of genotypes that were resistant and susceptible to the different nematodes (Figure 1, horizontal grouping).

Fragments common to all genotypes were obtained with the following combinations: F1/As2 (150 and 500 bp), S2/LM637 (500 bp), S2/As2 (500 bp), S2/As1 (850 bp), P-loop1/ GLPL1 (400 and $500 \mathrm{bp}$ ), and P-loop1/GLPL3 (100 and $500 \mathrm{bp}$ ).

Differential amplicons were detected between the groups of commercial genotypes, those resistant to Meloidogyne, and sources of resistance to SCN. For instance, genotypes resistant to nematodes of the genus Meloidogyne (BRS Raimunda, BRS 256 RR, PI 594427, BRSGO Paraíso, BRS Valiosa, PI 595099, BRS 211, and BRS Favorita) presented amplicons of $350 \mathrm{bp}$ (F1/As2), $150 \mathrm{bp}$ (s2/As3), and $800 \mathrm{bp}$ (s2/As3) in size (Figure 3, black arrows), which are also found in most of the commercial cultivars. The following fragments did not amplify as sources of resistance to SCN: PI 437654, PI 20332, PI 89772, Pickett, PI 88788, PI 548316, Hartwig, Peking, and PI 90736. Conversely, amplicons generated by the combinations S2/As2 (1050 bp), s2/As2 (1080 bp)

Genetics and Molecular Research 15 (3): gmr.15038562 
and s2/As2 (700 bp) only amplified in the PIs and in a few commercial genotypes, with most of these being resistant to more than two SCN races (Figure 1).

Cultivars from the group of commercial genotypes resistant or susceptible to the SCN races did not generate bands when amplified with the combinations s2/As2 (200, 1050, 1060 bp), P-loop1/GLPL1 (1020 bp), and P-loop 5/GLPL4 (450 bp), except for the genotypes Iara (R1,3), CD217 (R3 and R to M. incognita), TMG121 (R1,3 and MR 14) and Chapadões (R1, $2,3,4,5$ and 14). A 500-bp amplicon (s2/As1) was present in genotypes resistant to SCN and in commercial genotypes resistant to at least one race of this nematode (Figure 1, green arrow).

Based on these results, it was possible to observe that in most cases, genotypes resistant to nematodes of the genus Meloidogyne differed from those of the other groups by the absence of amplicons. In turn, in the commercial cultivars and PIs, groups of differential amplicons (absent in one group and present in another) could be verified, showing that the NBS domain is also important for SCN resistance. This will add to the literature, as genes for SCN resistance, rhgl and Rhg4, are described as belonging to the resistance gene class LLR-TM Kinase, and are therefore distinct from the NBS domain, which was the target of the present study.

To investigate the association between the fragments amplified by RGAs and QTLs of SCN resistance, RGA data from 25 genotypes with resistance and susceptibility to SCN were compared with data produced by SSRs associated with QTLs for resistance to SCN (Figure $3 \mathrm{C}$ and $\mathrm{D}$ ). In this analysis, genotypes related to resistance to the genus Meloidogyne were excluded. On the basis of microsatellites, genotypes with resistance to races 1, 3, and 14 were distinguished from genotypes with resistance to races 1 and 3, and also from the sources of resistance to SCN (Figure 3D). Moreover, QTLs for race 14 permitted separation of the commercial genotypes.

The cultivar Iara (resistant to races 1 and 3 ) was the most divergent of the commercial varieties, and was grouped with the susceptibility pattern Lee. In comparison, in the analysis of RGAs, the sources of resistance were separated from the commercial cultivars, but without distinction of groupings per race (Figure 3C), indicating that genes specific for race 14 were not assessed in this analysis.

\section{DISCUSSION}

The conservation of domains present in resistance genes in various taxonomic groups enables $R$ genes in the genomes of various species to be validated (Shen et al., 1998). Studies using RGA markers have successfully amplified sequences associated with resistance in various plant species (Soriano et al., 2005; Gururani et al., 2012). In the present study, primers based on the NBS domain of the resistance genes RP2, L6, and $N$ were used (Leister et al., 1996). These oligonucleotides generated polymorphisms in nematode-resistant and nematodesusceptible genotypes, resulting in clear differentiation between those resistant to SCN and those resistant to Meloidogyne spp. Kang et al. (2012) reported approximately 314 genes with NBS domains within the soybean genome that are associated with pathogen resistance, demonstrating the variability of these regions and the need to differentiate genomic regions that are associated with specific pathogens.

Analysis of RGA revealed that there was close proximity between genotypes, such as the cultivars BRS Valiosa and BRS256RR, which have cultivar Conquista in common in their genealogy. Therefore, the application of these markers in genealogy and inheritance studies is demonstrated.

Genetics and Molecular Research 15 (3): gmr.15038562 
Group 1 was formed by PIs, which are important sources of resistance to SCN. This was also noted by Vuong et al. (2015), who placed PIs (PI 88788 and PI 437654) within the same subgroup. This suggests that the sources of resistance have common progenitors, which contribute to the narrowing of the genetic basis of pathogen resistance. This finding is concerning, because the use of a common set of genotypes as a source of resistance has resulted in genetic modifications within populations of cyst nematodes, leading to "resistance breakage" (Vuong et al., 2015). Therefore, research that explores new sources of resistance and identifies new $\mathrm{R}$ genes is necessary.

Studies on the genetics of resistance to $\mathrm{H}$. glycines initially identified five genes in the soybean genome that are involved in the defense against SCN. The genes rhgl, rhg2, rhg3, Rhg4, and Rhg5 are found in PIs and are sources of resistance, and these include Peking (rhgl, rhg2 and rhg3) and PI 88788 (Rhg4 and Rhg5). These genes are distributed in more than 18 QTLs associated with resistance and have been widely studied. Despite their importance in resistance to H. glycines, rhgl and Rhg4 do not fit in the classes of R genes containing NBS domains, and instead possess LRR-TM and Kinase domains (Williamson and Kumar, 2006). The fragments generated in this study are not derived from these genes, but rather from other sequences that comprise the P-loop and GLPL motifs in the NBS domain. This observation highlights the interesting findings of the present analysis, including the cloning and characterization of these fragments in SCN resistance.

Most of the genotypes resistant to SCN are susceptible to nematodes of the genus Meloidogyne spp, just as those resistant to Meloidogyne are susceptible to SCN. The heat map analysis permitted the identification of fragments that are present in genotypes resistant to SCN (F1/As_200 bp; S2/As2_100 bp; S2/As1_500 bp), but absent in genotypes resistant to Meloidogyne. Furthermore, amplicons that are only present in genotypes resistant to Meloidogyne spp, but are absent in genotypes resistant to SCN (F1/As2_350 bp; S2/As3_150 $\mathrm{bp}$ and $800 \mathrm{bp}$ ) were identified. It is suggested that these fragments are associated with resistance to the nematodes studied here. Amplification of both sets of bands [those amplified only in genotypes resistant to SCN (F1/As_200 bp; S2/As2_100 bp; S2/As1_500 bp) or only in genotypes resistant to Meloidogyne spp (F1/As2_350 bp; S2/As3_150 bp and $800 \mathrm{bp}$ )] in commercial genotypes may require further resistance sequences that contain such motifs, which are not related to these nematodes, to be studied.

The genotypes of the group composed by PIs presented differential fragments that were obtained by the primer combination s2/As2 (of 1050, 1080, and $700 \mathrm{bp}$ ). These sequences are present in most of the PIs and are rarely present in commercial genotypes resistant to more than one cyst nematode race, suggesting an association with resistance to SCN.

The R genes identified against Meloidogyne spp possess the NBS domain (Williamson and Kumar, 2006; Gururani et al., 2012), which was also amplified in the present study. For resistance to the nematodes of this genus, the RGAs were able to discriminate between resistant and susceptible genotypes, without differentiation for resistance between species of $M$. incognita, $M$. javanica, and $M$. enterolobi. These data indicate that, for resistance to Meloidogyne spp, some factor related to the NBS domain confers ample resistance to the nematode, which is supported by reports showing that a small number of genes of greater effect control such resistance (Barbosa-da-Silva et al., 2005).

The narrow genetic basis of resistance to Meloidogyne spp originates from the use of the cultivar Bragg as a source of resistance for commercial genotypes, which hinders their differentiation (Dias et al., 2010). Hence, the cultivar Bragg should be used as a control for

Genetics and Molecular Research 15 (3): gmr.15038562 
resistance to Meloidogyne, and for a source of resistance. Conversely, in $\mathrm{H}$. glycines, many genes are involved in the resistance response in soybean, and inheritance of these genes is considered to be quantitative (Concibido et al., 2004). This way, the sources of resistance were differentiated based on the possession of regions distinct from those involved in SCN resistance.

The genotypes PI 595099 and PI 594427 are widely used in breeding programs (Beneventi et al., 2013), and are resistant to SCN and to Meloidogyne spp. Such genotypes are grouped together with the cultivars BRS Raimunda, BRS Valiosa, BRS Paraíso, BRS Favorita, BRS211, and BRS256RR, which are all resistant to Meloidogyne spp.

All primer classes used in this study (As, S2, P-loop, and GLPL) amplified in PI 595099 and PI 594427. The primers s1 and s2 amplified the P-loop motif, whereas As1, As2, and As3 amplified the GLPL motifs. The primers P-loop 1, P-loop 2, P-loop 3, P-loop 4, P-loop 5, and P-loop 6 (Kinase or P-loop motif), in association with LM637, GLPL1, GLPL2, GLPL3, GLPL4, and GLPL5 (GLPL motif), likewise amplified the P-loop and GLPL motifs, which are both from the NBS domain. Nevertheless, in the individual primer groupings (Figure 3 ), the GLPL/P-loop primer combinations were decisive in grouping the genotypes resistant to Meloidogyne spp. As observed following clustering with such primer sets (P-loop/GLPL), this was the only group that did not change when clustered using all primer classes (As, S2, P-loop, and GLPL). Therefore, the P-loop/GLPL combinations are important as they assess genome regions that are directly related to soybean resistance to the studied Meloidogyne species.

The relevance of primers containing P-loop motifs was confirmed by the heat map, from which we can infer the main primer combinations involved in the differentiation of genotypes. The set s1/As1 (500 bp) is given as the differential combination between the genotypes resistant to Meloidogyne spp and those resistant to SCN, since this band does not appear for genotypes resistant to Meloidogyne spp but is present in genotypes resistant to $\mathrm{SCN}$, and in commercial cultivars that are resistant to at least one race.

The clustering based on SSR data grouped genotypes with resistance to races 1 and 3 with those resistant to more than two races; this grouping was not obtained with RGAs. This indicates that the latter did not amplify all the genes associated with resistance to this nematode, and thus did not permit race specificity to be identified. QTLs of greater effect have been described for resistance to SCN, including GL G from the rhgl gene, which confers most of the resistance to race 3 of SCN, and various QTLs of smaller effect may be associated with race specificity (Concibido et al., 2004, Kadam et al., 2016). Therefore, it is presumed that genes originating from loci of smaller effect were not amplified in this study, as it was not possible to identify resistance to the different races of SCN. Hence, the group of genotypes resistant to more than one nematode race and the group of genotypes acting as sources of resistance to SCN were clustered more closely due to possible amplification of QTLs of smaller effect. This increased the distance of this group of genotypes, which possess resistance to only two nematode races.

It can be inferred that the analyzed QTLs help in determining associations of races specific to the SCN. While the RGAs used here (based on the NBS domain) did not confer racespecific resistance to cyst nematodes, they are associated with QTLs of generally greater effect. Therefore, the results of the present study show that specific motifs of the NBS domain amplified well in cultivars resistant to Meloidogyne spp, allowing the discrimination of genotype groups with regard to resistance to the studied nematodes. In addition, analyses with SSRs were more informative than those with RGAs, as SSRs discriminated genotypes based on their resistance to the different $\mathrm{SCN}$ races. Conversely, the heat map data permitted the identification of fragments

Genetics and Molecular Research 15 (3): gmr.15038562 
associated with resistance to SCN, which are responsible for the distinction between resistant and susceptible genotypes. Finally, GLPL motifs, which are amplified by the primer set P-loop/ GLPL, are directly associated with resistance to Meloidogyne spp.

The knowledge gained through these findings will help further subsidized breeding programs, thereby providing information on new candidate genes and increasing knowledge regarding $\mathrm{R}$ genes known to confer resistance to the nematodes studied.

\section{Conflicts of interest}

The authors declare no conflict of interest.

\section{ACKNOWLEDGMENTS}

We would like to thank FAPES (Fundação de Apoio à Pesquisa do Espírito Santo), CNPq (Conselho Nacional de Desenvolvimento Científico e Tecnológico), CAPES, and Federal University of Espírito Santo for financial support.

\section{REFERENCES}

Barbosa-da-Silva A, Wanderley-Nogueira AC, Silva RRM, Belarmino LC, et al. (2005). In silico survey of resistance (R) genes in Eucalyptus transcriptome. Genet. Mol. Biol. 28: 562-574. http://dx.doi.org/10.1590/S1415$\underline{47572005000400011}$

Beneventi MA, da Silva Jr OB, de Sá MEL, Firmino AAP, et al. (2013). Transcription profile of soybean-root-knot nematode interaction reveals a key role of phythormones in the resistance reaction. BMC Genomics 14: 1-17. http:// dx.doi.org/10.1186/1471-2164-14-322

Cai D, Kleine M, Kifle S, Harloff HJ, et al. (1997). Positional cloning of a gene for nematode resistance in sugar beet. Science 275: 832-834. http://dx.doi.org/10.1126/science.275.5301.832

Collins NC, Webb CA, Seah S, Ellis JG, et al. (1998). The isolation and mapping of disease resistance gene analogs in maize. Mol. Plant Microbe Interact. 11: 968-978.http://dx.doi.org/10.1094/MPMI.1998.11.10.968

Concibido VC, Diers BW and Arelli PR (2004). Decade of QTL mapping for cyst nematode resistance in soybean. Crop Sci. 44: 1121-1131. http://dx.doi.org/10.2135/cropsci2004.1121

Dias WP, Freitas VM, Ribeiro NR, Moita AW, et al. (2010). Reação de Genótipos de Soja a Meloidogyne enterolobii e M. ethiopica. Nematol. Bras 34: 220-225.

EMBRAPA (Empresa Brasileira de Pesquisa Agropecuária) (2011). Tecnologias de Produção de Soja, Região Central do Brasil 2012 e 2013. EMBRAPA, Londrina.

Flor HH (1971). Current status of the gene-for-gene concept. Annu. Rev. Phytopathol. 9: 275-296. http://dx.doi. org/10.1146/annurev.py.09.090171.001423

Gururani MA, Venkatesh J, Upadhyaya CP, Nookaraju A, et al. (2012). Plant disease resistance genes: current status and future directions. Physiol. Mol. Plant Pathol. 78: 51-65. http://dx.doi.org/10.1016/j.pmpp.2012.01.002

Jiao Y, Vuong TD, Liu Y, Li Z, et al. (2015). Identification of quantitative trait loci underlying resistance to southern rootknot and reniform nematodes in soybean accession PI 567516C. Mol. Breed. 35: 15-23. http://dx.doi.org/10.1007/ s11032-015-0330-5

Kadam S, Vuong TD, Qiu D, Meinhardt CG, et al. (2016). Genomic-assisted phylogenetic analysis and marker development for next generation soybean cyst nematode resistance breeding. Plant Sci. 242: 342-350. http://dx.doi.org/10.1016/j. plantsci.2015.08.015

Kanazin V, Marek LF and Shoemaker RC (1996). Resistance gene analogs are conserved and clustered in soybean. Proc. Natl. Acad. Sci. USA 93: 11746-11750. http://dx.doi.org/10.1073/pnas.93.21.11746

Kang YJ, Kim KH, Shim S, Yoon MY, et al. (2012). Genome-wide mapping of NBS-LRR genes and their association with disease resistance in soybean. BMC Plant Biol. 12: 1-13.http://dx.doi.org/10.1186/1471-2229-12-139

Kim M, Hyten DL, Bent AF and Diers BW (2010). Fine mapping of the SCN resistance locus rhg1-b from PI 88788. Plant Genome 3: 81-89. http://dx.doi.org/10.3835/plantgenome2010.02.0001

Lei X, Yao Q, Xu X and Liu Y (2014). Isolation and characterization of NBS-LRR resistance gene analogues from mango. Biotechnol. Biotechnol. Equip. 28: 417-424.http://dx.doi.org/10.1080/13102818.2014.931706

Genetics and Molecular Research 15 (3): gmr.15038562 
Leister D, Ballvora A, Salamini F and Gebhardt C (1996). A PCR-based approach for isolating pathogen resistance genes from potato with potential for wide application in plants. Nat. Genet. 14: 421-429.http://dx.doi.org/10.1038/ng1296-421

McDonald MB, Elliot LJ and Sweeney PM (1994). DNA extraction from dry seeds for RAPD analyses in varietal identification studies. Seed Sci. Technol. 22: 171-176.

Pan Q, Liu Y, Budai-Hadrian O, Sela M, et al. (2000). Comparative genetics of nucleotide binding site-leucine rich repeat resistance gene homologues in the genome of two dicotyledons: tomato and Arabdopsis. Genetics 155: 309-322.

Sanseverino W and Ercolano MR (2012). In silico approach to predict candidate R proteins and to define their domain architecture. BMC Res. Notes 5: 1-11. http://dx.doi.org/10.1186/1756-0500-5-678

Santana FA (2008). Seleção assistida e diversidade genética de fontes de resistência ao nematóide de cisto da soja. Master's thesis, Universidade Federal de Viçosa, Viçosa. Available at [http://www.locus.ufv.br/handle/123456789/4687].

Sekhwal MK, Li P, Lam I, Wang X, et al. (2015). Disease resistance gene analogs (RGAs) in plants. Int. J. Mol. Sci. 16: 19248-19290. http://dx.doi.org/10.3390/ijms160819248

Shen KA, Meyers BC, Islam-Faridi MN, Chin DB, et al. (1998). Resistance gene candidates identified by PCR with degenerate oligonucleotide primers map to clusters of resistance genes in lettuce. Mol. Plant Microbe Interact. 11: 815-823. http://dx.doi.org/10.1094/MPMI.1998.11.8.815

Soriano JM, Vilanova S, Romero C, Llácer G, et al. (2005). Characterization and mapping of NBS-LRR resistance gene analogs in apricot (Prunus armeniaca L.). Theor. Appl. Genet. 110: 980-989. http://dx.doi.org/10.1007/s00122-005$\underline{1920-0}$

Thakur M and Sohal BS (2013). Role of elicitors in inducing resistance in plants against pathogen infection: a review. ISRN Biochem. 2013: 762412.http://dx.doi.org/10.1155/2013/762412

Vuong TD, Sonah H, Meinhardt CG, Deshmukh R, et al. (2015). Genetic architecture of cyst nematode resistance revealed by genome-wide association study in soybean. BMC Genomics 16: 1-13. http://dx.doi.org/10.1186/s12864-015$\underline{1811-\mathrm{y}}$

Williamson VM and Kumar A (2006). Nematode resistance in plants: the battle underground. Trends Genet. 22: 396-403. http://dx.doi.org/10.1016/j.tig.2006.05.003

Xiao L, Zhong YP, Wang B and Wu TL (2014). Mapping an aphid resistance gene in soybean [Glycine max (L.) Merr.] P746. Genet. Mol. Res. 13: 9152-9160.http://dx.doi.org/10.4238/2014.November.7.2

Yu YG, Buss GR and Maroof MAS (1996). Isolation of a superfamily of candidate disease-resistance genes in soybean based on a conserved nucleotide-binding site. Proc. Natl. Acad. Sci. USA 93: 11751-11756.http://dx.doi.org/10.1073/ pnas.93.21.11751

Genetics and Molecular Research 15 (3): gmr.15038562 